\title{
3D Numerical Simulation of Turbulent Mixed Convection in a Cubical Cavity Containing a Hot Block
}

\author{
A. Bouras ${ }^{1}$, S. Bouabdallah ${ }^{1 \dagger}$, B. Ghernaout ${ }^{1}$, M. Aric ${ }^{2}$, Y. Cherif $^{3}$ and E. Sassine ${ }^{4}$ \\ ${ }^{1}$ LME, Laboratory of Mechanics, University of Laghouat, 03000, Algeria \\ ${ }^{2}$ Mechanical Engineering Department, Engineering Faculty, Kocaeli University, 4100, Turkey \\ ${ }^{3}$ LGCgE Laboratory, University of Artois, ULR 4515, Béthune, F-62400, France \\ ${ }^{4}$ Laboratory of Applied Physics (LPA-GMTER), Lebanese University, Lebanon \\ ${ }^{\dagger}$ Corresponding Author Email: s.bouabdallah@lagh-univ.dz.
}

(Received January 19, 2021; accepted July 6, 2021)

\begin{abstract}
The considerable quantities of heat transfer are dissipated during the operating electronic/electrical systems and have harmful effects on the operating time. So; to keep these systems in good working condition, the location of efficient mechanical cooling systems is essential. The heat transfer rate in an enclosure intensely depends on the combination of geometrical and physical parameters. For this purpose, a 3D Numerical simulation of turbulent mixed convection in a cubical cavity containing an internal heat source in its middle was carried out. The cavity has an inlet port at the lower left face area and an outlet port located in the upper right face area. The analyses are performed for air at ambient circumstances $(\mathrm{Pr}=0.71)$ and the variation of interval for Richardson number (Ri) is chosen between 0.01 and 30 to investigate three situations: dominated forced convection, natural convection, and mixed convection for a fixed dimension of the enclosure in turbulent regimes $\left(\mathrm{Gr}=10^{9}\right)$. The effects of the variation of $\mathrm{Ri}$, the dimensionless time, and the dynamic parameters on the thermal flow and fluid flow phenomena are presented and discussed. The obtained results show an exchange between the forces of pressure and of buoyancy in the studied interval and a strong dependence between the geometrical parameters and the heat transfer rate, and then the correlations of the combination of the parameters were proposed.
\end{abstract}

Keywords: Mixed convection; Turbulent flow; Cooling; Heat source; 3D convection; Cavity.

\section{NOMENCLATURE}

g gravitational acceleration

$\mathrm{K}$ dimensionless turbulent kinetic energy

$k^{*} \quad$ dimensionless thermal conductivity

$\mathrm{k} \quad$ turbulent kinetic energy

L length of cavity

$\mathrm{P} \quad$ dimensionless pressure

$p \quad$ pressure

$\mathrm{s} \quad$ perimeter of the hot source

$\mathrm{T} \quad$ dimensional temperature

$\mathrm{t} \quad$ time

$\mathrm{U}, \mathrm{V}, \mathrm{W}$ dimensionless velocity components

$\mathrm{u}, \mathrm{v}, \mathrm{w} \quad$ velocity components

$\mathrm{X}, \mathrm{Y}, \mathrm{Z}$ dimensionless Cartesian coordinates

$\Delta \tau \quad$ dimensionless time step

$\varepsilon$ dimensionless turbulent dissipation rate

$\varepsilon^{*} \quad$ turbulent dissipation rate

$\theta \quad$ dimensionless temperature

$\lambda$ thermal conductivity

$v \quad$ dimensionless kinematic viscosity

$v^{*} \quad$ dimensionless kinematic viscosity

\section{$\mathrm{x}, \mathrm{y}, \mathrm{z}$ dimensional Cartesian coordinates}

Dimensionless number

Gr Grashof number

Pr Prandtl number

$\mathrm{Nu} \quad$ Nusselt number

$\mathrm{Ra} \quad$ Rayleigh number

Re Reynolds number

$\mathrm{Ri} \quad$ Richardson number

\section{Greek Symbols}

$\alpha \quad$ thermal diffusivity

$\beta \quad$ thermal expansion coefficient

K von Karman constant

$\tau$ dimensionless time

\begin{tabular}{ll}
\multicolumn{2}{l}{ Subscripts } \\
Avg & average \\
c & cold \\
h & hot
\end{tabular}


$v^{*} \quad$ dimensionless turbulent kinematic

$\rho \quad$ density

\section{INTRODUCTION}

In recent decades, the field of computational fluid dynamics of mixed convection in vented enclosures has been the focus of many researches due to the important complexity of coupling between the fluid flow and the energy transport. This kind of flow is encountered in numerous applications of engineering, e.g. cooling of electronic components, design of buildings, furnaces, air conditioning, air cooling, nuclear reactors, and others.

Literature survey shows that many studies have been performed, which consider two-dimensional (2D) convection in a heated cavity. A square shape cavity with partially heated surfaces was considered by Nardini et al. (2016), where the free convection in the enclosure containing five separate heat sources positioned on the walls of the cavity for various Rayleigh numbers was analyzed experimentally and numerically. Ventilated cavities having a square/circular heat source have been numerically investigated for different boundary conditions, Rayleigh numbers, Richardson numbers, heat source diameters, and the ratios of thermal conductivity of the solid to that of the fluid (Bouabdallah et al. 2016; Burgos et al. 2016, Rahman et al. 2008, 2009, 2012; Gupta et al. 2015, Chati et al. 2021a). Kuznetsov and Sheremet (2010) numerically examined laminar conjugate heat transfer in a rectangular area having finite thickness heat conducting walls at local heating. The impacts of the Reynolds number, Grashof number, and the dimensionless time on the flow structure and heat transfer characteristics have been investigated in detail. The diagram of the heat convection modes in the presence of conducting solid walls has been obtained. They directed that the analysis of heat convection modes in a typical subsystem of the electronic equipment is oriented not only toward applied development in microelectronics but also it can be considered as a test database at the creation of numerical codes of convective heat transfer simulation in complicated energy systems.

Ivan and Mikhail (2018) have examined the mixed convection in an open enclosure that includes a local heater. They studied the effect of formation of different vortices, and the size and location of heat source size on the heat transfer, and stated that incrementing $R i$ number has a remarkable effect on the strength of convective vortices. Mixed convection inside an open cavity in channel with heated bottom wall and with different sizes of heat source was numerically investigated by Burgos et al. (2016). Laouira et al. (2020) explored the influences of a heat source in different lengths on the heat transfer in an open trapezoidal cavity inside a horizontal channel numerically. The results indicated an increase in the both local and the mean $\mathrm{Nu}$ numbers as the heat source is lengthened. Kadari et al. (2018) found that the distribution of temperature is notably dependent on the size of the $\begin{array}{ll}\text { in } & \text { Inlet } \\ \mathrm{t} & \text { turbulente }\end{array}$

heat source, and both average and local $N u$ numbers increase when the local heat source is extended.

In another case, the heat source in an enclosure has been numerically examined by Afolabi et al. (2019). They maintained the cavity with insulated horizontal walls and vertical cold constant temperature walls while the heat source at hot and constant temperature is placed on the center. The results show that there is a significant influence of $R a$ number on the heat transfer thus the temperature distribution in the cavity.

The heat transfer by forced convection from two equal circular cylinders located at the mid-section of cavity with a square shape was examined. The obtained results showed the augmentation in heat transfer rate with increasing the distance between cylinders (Helmaoui et al. 2020). Laidoudi et al. (2020) exhibited the profound influence of inlet and outlet ports on the heat transfer from the circular cylinders. Koufi et al. (2017) also emphasized the effects of the openings in turbulent heat transfer via mixed convection inside vented enclosures. Mosharrof et al. (2019) compared numerical simulations of mixed-convection handled as twoand three -dimensional inside a vented cavity. The results revealed that the rate of heat transfer by convection raises strikingly inside the ventilated room at high $R e$ and $R i$ numbers. Gokulavani et al. (2018) explored the free convection in cavity containing a heated baffle at its center positioned vertically or horizontally with different configurations of the open cavity on vertical walls, for various Rayleigh numbers, Reynolds numbers and aspect ratios. The vertical baffle was shown to be more effective for augmenting heat transfer compared to the horizontal baffle.

In recent years, numerous studies regarding the three-dimensional convection in a heated cavity have been presented. Authors (Afrid and Zebib 1991; Amirouche and Bessaïh 2012) numerically simulated the convection cooling of some cubic heated sources on vertical channel, representing the case of electronic chips cooling in the applications of electronic industry. In order to investigate the influence of the ratio of thermal conductivities of air/solid, and $\mathrm{Ra}$ and $R e$ numbers on heat transfer inside the channel, numerical studies have been conducted considering the mixed convective flow in a 3D enclosure (Stiriba et al. 2013; Rajesh et al. 2014). The effects of temperature distribution, velocity, and buoyancy forces exerting perpendicularly to the flow were studied for different Richardson and Reynolds numbers. Fontana et al. (2013) explored the free convection numerically in a three-dimensional model inside an open cubic enclosure containing a heat source. Choi et al. (2015) simulated the 3D free convection in a cubic closed space with an internal circular cylinder for various $\mathrm{Ra}$ numbers and positions of the cylinder which was vertically changed along the centerline of the cubic. Considering the mixed 
convection in a ventilated cubic enclosure for various $R a$ numbers, numerical and experimental investigations performed by Rodriguez et al. (2015) reported a difference of $2 \%$ between the calculated and measured temperatures. To obtain heat transfer coefficients and temperature profiles in a cube containing a rectangular heat source, Piña-Ortiz et al. (2018) compared six of most recurrently used turbulence models with experimental data. They found that when the heat source switch is on, the lowest mean error $(0.84 \%)$ was attained by the realizable $\mathrm{k}-\varepsilon$ model. On the other hand, threedimensional numerical studies of ventilated cavity with partially heated surface, with differently heated side walls or with isothermal heating block studied by Doghmi et al. (2020). The results are presented for various combinations of thermal controlling parameters. They found that for the low Re number the heat transfer process is carried out only by conduction. Also, the highest thermal performance is achieved by reducing the heating section dimension. The numerical free convection study in a three-dimensional cubical enclosure including a thermally active plate by Purusothaman et al. (2016) indicated the effect of the active plate size on the flow and convective heat exchange and inside the cubical enclosure. Alshomrani et al. (2019) also considered 3D free convection in a cubical cavity with different positions of heater and cooler, and they indicated the significant role of cooler location, $R a$ number and aspect ratio in the energy transport convective cooling flow inside the enclosure. Recently, Bouabdallah et al. (2020) studied numerically the 3D forced convection in a cubic cavity containing two cylindrical heat sources in the middle and Chati et al. (2021b) numerically analyzed the turbulent mixed convective heat transfer in a ventilated enclosure with a cylindrical/cubical heat source. They showed that the ventilation efficiency of the cavity including the cylindrical heat source is better.

The obtained results show a strong dependence between the geometrical conditions and the structure of the dynamic and thermal field of the forced flow convection. In fact, the turbulent regime is hardly used for cooling heat sources because of its very energy consumption. But, there are situations what mechanical cooling must be very efficient in a turbulent regime with a considerable heat transfer at the source according to the geometrical parameters. On the other hand for structural flow, the turbulent model gives more information on the formation of the tourbillion and the necessary zone for cooling in the box from the heat source. The literature review proves that threedimensional turbulent mixed convection studies in enclosures including a heating block are limited which is the reason behind the physical model selection in the present numerical work. Thus, studying the influences of conjugated $R i$ numbers on the $3 \mathrm{D}$ transient mixed convection in turbulent regime in a cubic cavity that contains a square cylinder heat source is the goal of the present work. The impact of different governing parameters on the flow and heat transfer is investigated.

\section{Numerical MODELING}

\subsection{Physical Model}

The considered physical system is displayed schematically in Fig. 1 The system consists of a cubical cavity with two openings and contains a hot block. The two openings and the source have the same width "L", and the same height " $h$ ", which is $\mathrm{h}=\mathrm{L} / 5$. The heat source in the form of square cylinder with dimension of " $\mathrm{D}$ " is placed in the center of the enclosure. The walls are maintained adiabatic and the heat source is kept at isothermal high temperature of $\mathrm{T}_{\mathrm{h}}$.

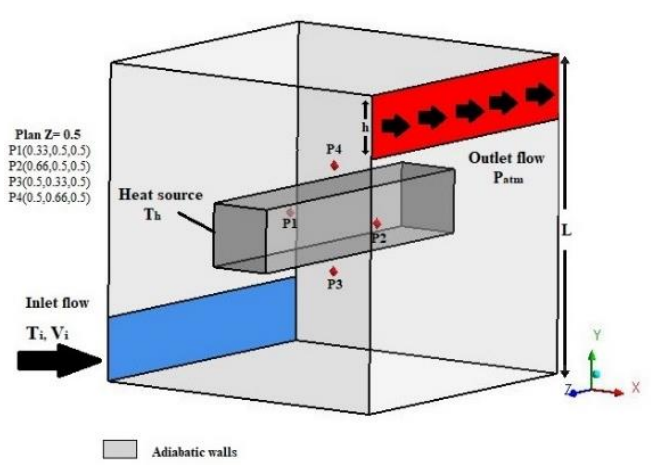

Fig. 1. Geometric configuration, boundary condition of the problem and points for monitoring time-dependent temperature.

The governing equations formulated in dimensionless vector potential functions and vorticity vector have been solved using implicit finite difference method of the second order accuracy. The following assumptions have been made for the analysis of Three-dimensional turbulent mixed convection. The working fluid (air) is Newtonian, flow is incompressible with negligible viscous dissipation, the fluid properties are constant except for the density in the buoyancy term that follows the Boussinesq approximation. Since the temperature interval in the study is considered low, the radiative heat transfer is neglected beside the convective phenomena.

\subsection{Governing Equations}

Using $\mathrm{k}-\varepsilon$ model for turbulent regimes and dimensionless variables of $\tau=\frac{t U_{0}}{L}, X=\frac{x}{L}, Y=$ $\frac{y}{L}, Z=\frac{z}{L}, U=\frac{u}{U_{0}}, V=\frac{v}{U_{0}}, W=\frac{w}{U_{0}}, \theta=\frac{T-T_{c}}{T_{h}-T_{c}}$, $P=\frac{p-p_{0}}{\rho U_{0}{ }^{2}}, K=\frac{k}{U_{0}^{2}}$ and $\varepsilon=\frac{\varepsilon^{*}}{\left(\alpha^{3} / L^{4}\right)}$ respectively for time, coordinates, velocities components, temperature, pressure, kinetic energy and turbulent dissipation rate, the dimensionless governing equations take the following forms:

$\vec{\nabla} . V=0$ 
A. Bouras et al. / JAFM, Vol. 14, No. 6 pp. 1869-1880, 2021.

$$
\begin{aligned}
& \frac{\partial U}{\partial \tau}+\vec{\nabla} \cdot(\vec{V} U)=-\frac{\partial P}{\partial X}+\operatorname{Pr} \nabla \cdot\left[\left(v^{*}+v_{t}^{*}\right) \nabla U\right] \\
& \frac{\partial V}{\partial \tau}+\vec{\nabla} \cdot(\vec{V} V)=-\frac{\partial P}{\partial Y}+\operatorname{Pr} \nabla \cdot\left[\left(v^{*}+v_{t}^{*}\right) \nabla V\right]+ \\
& \operatorname{Ra} \operatorname{Pr} \theta
\end{aligned}
$$

$\frac{\partial W}{\partial \tau}+\vec{\nabla} \cdot(\vec{V} W)=-\frac{\partial P}{\partial Z}+\operatorname{Pr} \nabla \cdot\left[\left(v^{*}+v_{t}^{*}\right) \nabla W\right]$

$\frac{\partial \theta}{\partial \tau}+\vec{\nabla} \cdot(\vec{V} \theta)=\left[\left(k^{*}+\alpha_{t}^{*}\right) \nabla \theta\right]$

$\frac{\partial K}{\partial \tau}+\vec{\nabla} \cdot(\vec{V} K)=\operatorname{Pr} \nabla \cdot\left[\left(v^{*}+\frac{v_{t}^{*}}{\sigma_{k}}\right) \nabla K\right]-\varepsilon-\mathrm{G}+\mathrm{P}$

$\frac{\partial \varepsilon}{\partial \tau}+\vec{\nabla} \cdot(\vec{V} \varepsilon)=\operatorname{Pr} \nabla \cdot\left[\left(v^{*}+\frac{v_{t}^{*}}{\sigma_{\varepsilon}}\right) \nabla \varepsilon\right]+C_{1} \cdot \mathrm{P}-$

$C_{2} \varepsilon-C_{3} \cdot G \cdot \frac{\varepsilon^{2}}{K}$

The obtained dimensionless numbers are Reynolds number $\operatorname{Re}=L \cdot U_{0} / v$, Prandtl number, $\operatorname{Pr}=v / \alpha$, Grashof number $G r=$ g. $\beta \cdot \Delta T \cdot L^{3} / v^{2}$, Rayleigh number $R a=G r \cdot P r$, and Richardson number $R i=$ $G r / R e^{2}$. The parameters $P o$ and $G$ stand for the productions of turbulent kinetic energy due to shear and buoyancy forces, respectively.

$$
\begin{aligned}
& P o=P r \cdot v_{t}^{*}\left[\left(\frac{\partial U}{\partial Y}+\frac{\partial V}{\partial X}\right)^{2}+\left(\frac{\partial V}{\partial Z}+\frac{\partial W}{\partial Y}\right)^{2}+\right. \\
& \left.\left(\frac{\partial W}{\partial X}+\frac{\partial U}{\partial Z}\right)^{2}+2\left(\left(\frac{\partial U}{\partial X}\right)^{2}+\left(\frac{\partial V}{\partial Y}\right)^{2}+\left(\frac{\partial W}{\partial Z}\right)^{2}\right)\right] \\
& G=R a \frac{P r^{2}}{P r_{t}} v_{t}^{*} \frac{\partial \theta}{\partial Y}
\end{aligned}
$$

The constants of the standard $(\mathrm{k}-\varepsilon)$ model are: $\mathrm{C}_{1}$ $=1.44 ; \mathrm{C}_{2}=1.92 ; \sigma_{\varepsilon}=1.30 ; \sigma_{k}=1.00 ; \mathrm{C}_{\mu}=0.09$ (Amirouche and Bessaïh 2012). The boundary conditions are given below:

$$
\begin{aligned}
& X=0 ; 0 \leq Y \leq 0.2 ; 0 \leq Z \leq 1: \\
& U=1 ; V=0 ; \theta=0 \\
& X=0 ; 0.2 \leq Y \leq 1 ; 0 \leq Z \leq 1: \\
& U=V=0 ; \frac{\partial \theta}{\partial X}=0 \\
& X=1 ; 0 \leq Y \leq 0.8 ; 0 \leq Z \leq 1: \\
& U=V=0 ; \frac{\partial \theta}{\partial X}=0 \\
& X=1 ; 0.8 \leq Y \leq 1 ; 0 \leq Z \leq 1: \\
& \frac{\partial U}{\partial X}=\frac{\partial V}{\partial X}=\frac{\partial \theta}{\partial X}=0
\end{aligned}
$$

$0 \leq X \leq 1 ; Y=0 ; 0 \leq Z \leq 1:$
$U=V=0 ; \frac{\partial \theta}{\partial Y}=0$

$0 \leq X \leq 1 ; Y=1 ; 0 \leq Z \leq 1:$

$U=V=0 ; \frac{\partial \theta}{\partial Y}=0$

$0 \leq X \leq 1 ; 0 \leq Y \leq 1 ; Z=0$

$U=V=0 ; \frac{\partial \theta}{\partial Y}=0$

$0 \leq X \leq 1 ; 0 \leq Y \leq 1 ; Z=1$

$U=V=0 ; \frac{\partial \theta}{\partial Z}=0$

At the heat source:

$\left.\begin{array}{rl}0.4 & \leq X \leq 0.6 \\ 0.4 & \leq Y \leq 0.6 \\ 0 & \leq Z \leq 1\end{array}\right\}: \mathrm{U}=\mathrm{V}=\mathrm{W}=0 ; \theta=1$

The equations of the turbulent kinetic energy " $\mathrm{K}$ " and its dissipation " $\varepsilon$ ", Eqs. (6) and (7) were solved only in the fluid region. The turbulent kinetic energy is set to zero at solid walls, and its normal gradients are prescribed as zero at the other boundaries. The equation of dissipation is not solved at nodes which are adjacent to the wall, in this region, the production and dissipation of turbulent kinetic energy are equal, which leads to an approximation of the dissipation, $\varepsilon=\mathrm{C}^{0.75}$. $\mathrm{K}^{1.5} /(\mathrm{K} . \mathrm{dl})$ where $\mathrm{dl}$ is the distance from the wall to the first node, and $\mathrm{K}$ is the von Karman constant and equal to 0.41 (Amirouche and Bessaïh 2012).

To justify the use of the standard k- $\varepsilon$ model for solving turbulence regimes, a comparative study of different turbulent models including $\mathrm{k}-\omega, \mathrm{k}-\mathrm{k}$; L- $\omega$, RSM, SAS, and SST was performed. Figure 2(a-b) show the turbulent kinetic energy and velocity for different turbulent models in the middle of the cavity for $R i=20$. The results show that for the studied case, the curves of turbulent kinetic energy and velocity along the cavity have almost the same variation for all the turbulent models with small difference between each model, where the rate of change between $\mathrm{k}-\varepsilon$ and other models does not exceed $3 \%$. However, since the computational time of $\mathrm{k}-\varepsilon$ model is much less than that of other models which is pointed out in the study of Piña-Ortiz et al. (2018). Also, the $\mathrm{k}-\varepsilon$ model is selected for the further analysis.

The average Nusselt number is defined by:

$N u_{\text {avg }}=\int_{0}^{s} \int_{0}^{l} \frac{\partial \theta}{\partial n} \cdot d n$

where $n$ is normal to the hot solid body surface and $s$ and is the perimeter of hot solid body. 


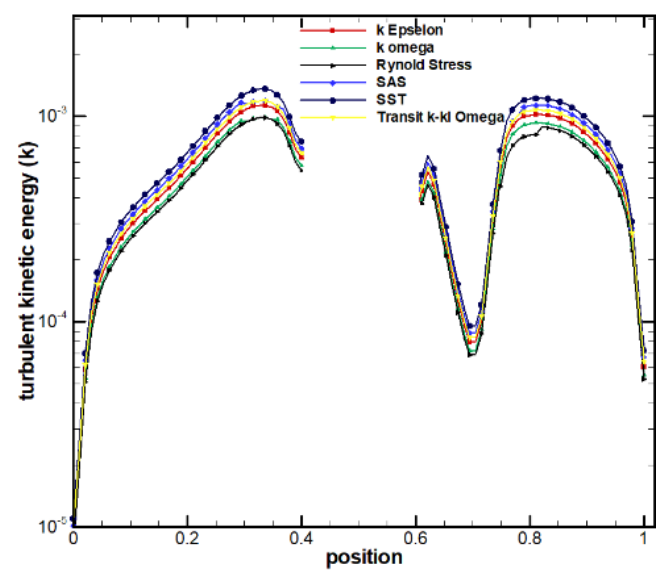

a) Turbulent kinetic energy

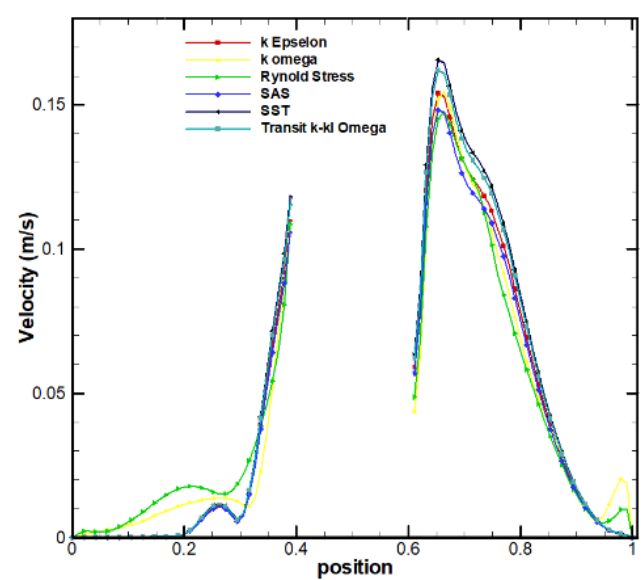

b) Velocity

Fig. 2. Different turbulent model $(R i=20)$.

\subsection{Numerical Method}

Finite volume method is utilized to obtain the numerical solution of the set of Eqs. (1-9), regarding the boundary conditions given in Eqs. (10a-h). Time marching is handled by the fully implicit scheme. For the convective terms, second order upwind scheme is employed and the algorithm applied for coupling the velocity and pressure fields is SIMPLER (Rahman et al. 2009; Bouabdallah et al. 2020 ). The convergence is attained when the residuals are less than $10^{-4}$. Commercial software ANSYS Fluent 15 is used as a solver. The utilized numerical model is validated considering the experimental data presented by Calcagni et al. (2005). Who conducted an experimental work on the free convection in a cubic cavity containing a local heat source with uniform surface temperature. The enclosure was heated by a local heat source positioned on the lower side and was cooled from vertical walls. The other walls of the cavity are adiabatic. We kept the same conditions where we used the same Rayleigh numbers $(R a)$ and the same values of the heat source length. We have also made a comparison of average Nusselt numbers and 3D temperature fields in the cavity with the results obtained by Gibanov and Sheremet (2017). They conducted a study on the free convective flow inside a cubic enclosure with an isothermal local heat source at a constant temperature.

The cubic cavity is heated by the local heat source mounted on the lower wall and cooled from two opposite vertical walls, while the other walls are adiabatic. The same conditions are established, for $R a=10^{4}-10^{6}$ and $\mathrm{I} / \mathrm{L}=0.05-0.35$ where $\mathrm{L}$ indicated the length of the cubical cavity and I is the distance between the left wall and heat source. Figures 3, 4 and 5; indicates a high agreement of the results, which confirms the validity of our numerical procedure.

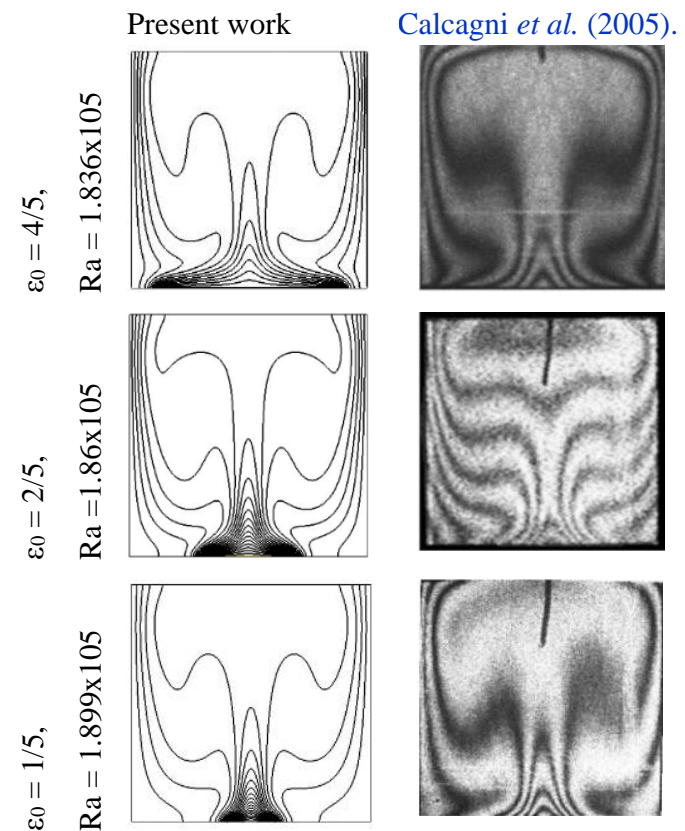

Fig. 3. Validation results regarding the experimental data of Calcagni et al. (2005) in terms of isotherms for various dimensions of the cavity and heat source.

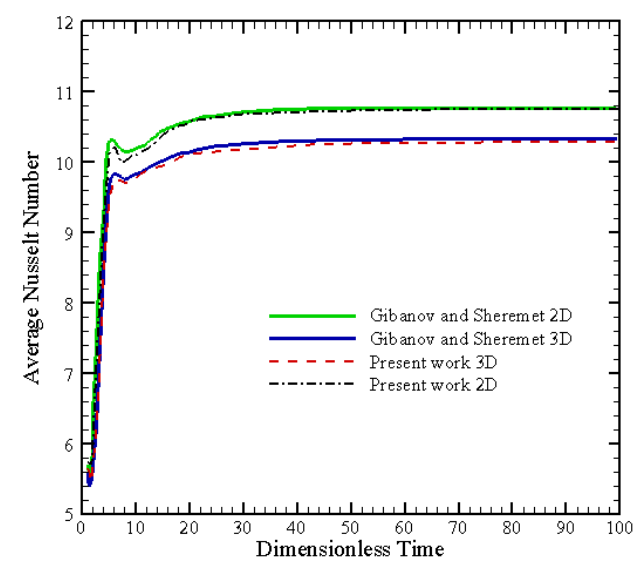

Fig. 4. Time evolution of average Nusselt number in 2D and 3D studies: Comparison of results with those of Gibanov and Sheremet (2017). 


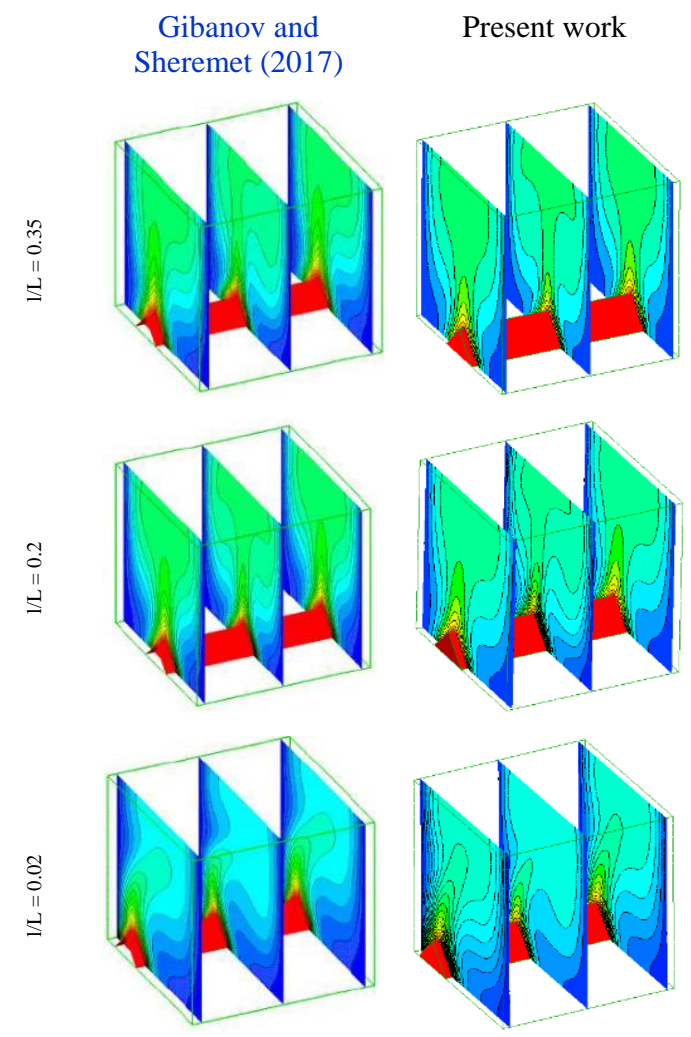

Fig. 5. 3D temperature fields $(R a=105$ at $\tau=100$ for: $1 / \mathrm{L}=0.05, \mathrm{l} / \mathrm{L}=0.2, \mathrm{l} / \mathrm{L}=0.35$ ): Comparison of our results with those obtained by Gibanov and Sheremet (2017).

The grid independence test was also conducted in this work to confirm that the numerical solution is independent than grid spacing. With this purpose, five different meshes in the computational domain were examined; $2 \times 10^{5}, 3 \times 10^{5}, 5 \times 10^{5}, 7 \times 10^{5}, 9 \times 10^{5}$ and $10^{6}$ nodes.

From Fig. 6 which depicts the variation of average $\mathrm{Nu}$ number on the hot surface for different mesh sizes, it is concluded that the mesh with $9 \times 10^{5}$ nodes can be utilized for the further examination.

Figure 7 illustrates the temporal evolution of the average Nusselt number sensitivity calculated for different time steps ranging from $\Delta \tau=1$ to $\Delta \tau=10^{3}$. As seen in the figure, for different time steps, the average Nusselt number declines until a certain time $(\tau=25)$ and then starts to rise with elapsing time. After reaching the steady-state regime around $\tau=$ 100 , the temperature variation almost levels off.

The results show a monotone and asymptotic convergence leaning toward their limiting trend as $\Delta \tau$ decreases. It is noted that the average $N u$ number increases with decreasing of $\Delta \tau$ and starts to converge more closely from $\Delta \tau=10^{-2}$, which is the dimensionless time step used for our examination.

\section{RESULTS AND DISCUSSIONS}

The Grashof number is set to $10^{9}$ in the problem taken into account, which corresponds to the turbulent flow regime. The computations are considered for various Richardson numbers ranging from $R i=0.01$ to 30 , which indicates the significance of natural convection versus forced convection. Reynolds number, which is defined regarding the width of the inlet, is varied to obtain the studied Richardson number.

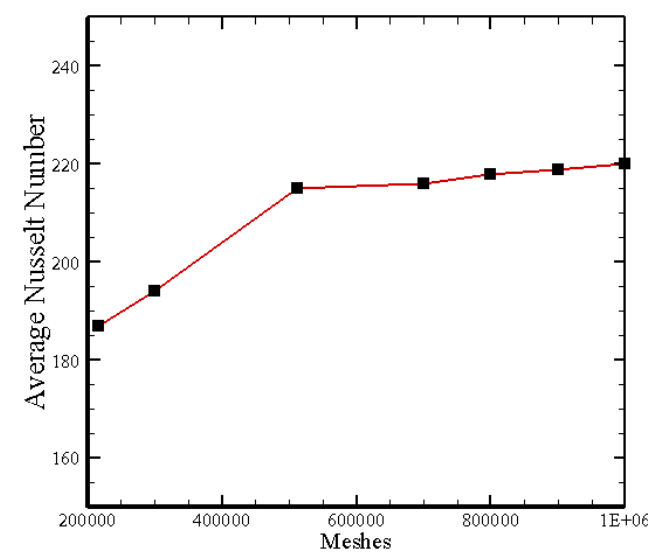

Fig. 6. Average $N u$ variations on the surface of heat source for different grid sizes.

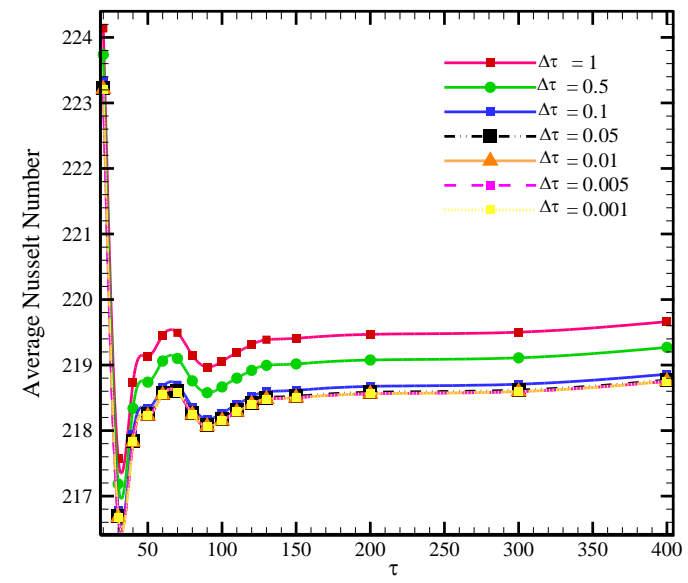

Fig. 7. Time step independency test.

\subsection{Steady heat and flow field}

Figure 8 displays the temperature profiles in the middle part of the enclosure. The presence of sharp temperature gradients in the vicinity of the heat source is noted for dimensionless temperature is maximum $(\theta=1)$. We can also find values (between two maximum values in the middle of the cavity) that correspond to the temperature of the two vertical left and right) hot walls of the heat source. Also low values are noted corresponding to the two ends of the enclosure. The effect of $R i$ on the temperature can be analyzed in two parts. For the $R i$ values between $0.01<R i<1$, a progressive temperature increment is observed with increasing $R i$. However, for $1<R i<30$, the temperature decreases with increasing $\mathrm{Ri}$ (i.e. for $1<R i<30$ ). 
For low values of $R i(0.01<R i<1)$, the dominant mode of the heat transfer is forced convection. The temperature rises with the increment of $R i$ number due to the decrement of the air particle velocities. This reduces the effectiveness of the influence of the air convection on the heat source, and finally causes a significant increase in the temperature.

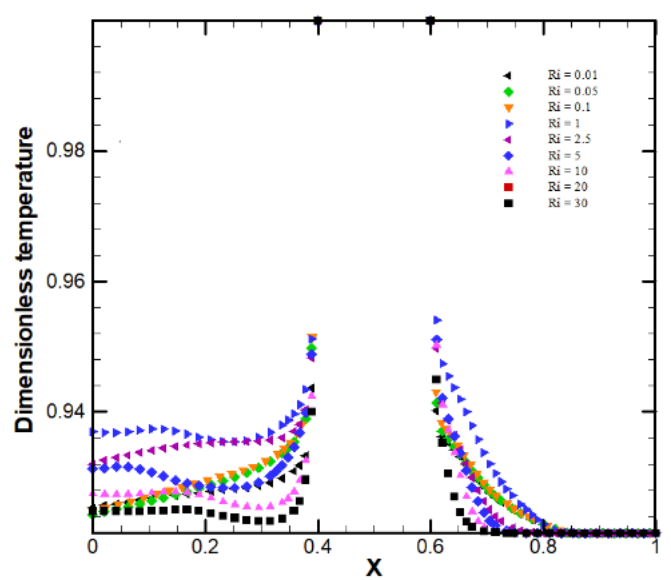

Fig. 8. Dimensionless temperature variation in the middle of the cavity according to the $x$ direction for different $R \boldsymbol{R}$.

For high values of $R i$ number $(1<R i<30)$ characterized by enhancement of interaction between the buoyancy force and pressure force and the buoyancy effects become dominant. The temperature and velocity fields are respectively displayed in Fig. 9 and Fig. 10 for different $R i$ values to present a detailed image of the velocity and temperature distributions. In Fig. 9, for different $R i$ numbers due to the presence of the hot block, the high temperatures are noticed near the boundaries of the heat source, the isotherms are concentrated around the block that reveal the significance effect of $R i$ on the thermal layers thickness. In addition, the temperature gradients are noticed to be low in the region away from the hot walls for low values of $R i$. With the increment in $R i$, isotherms in the domain near the heated surfaces get closer to each other, resulting in stronger temperature gradients in these regions.

Since outlet port is located on the upper right face, at high $R i$, the buoyancy is maximum and hence more fluid particles float upward, the hot fluid moves towards upper zone. Due to this, the isotherms are more packed near the upper wall.

Figure 10 shows that when Richardson number is low $R i \leqslant 1$, the buoyancy force is low and hence the flow is uniform. When the buoyancy force is increased, stratifications occur in vicinity of the block. As result, when the buoyancy is amplified at $R i \geqslant 10$, the increasing convection creates recirculation cell around the hot block. Richardson number plays has a big impact on the velocity field since the largest vertical velocity area is displaced from the bottom of the enclosure under the heat source into the central position over the heat source toward the outlet, with increasing $R i$.
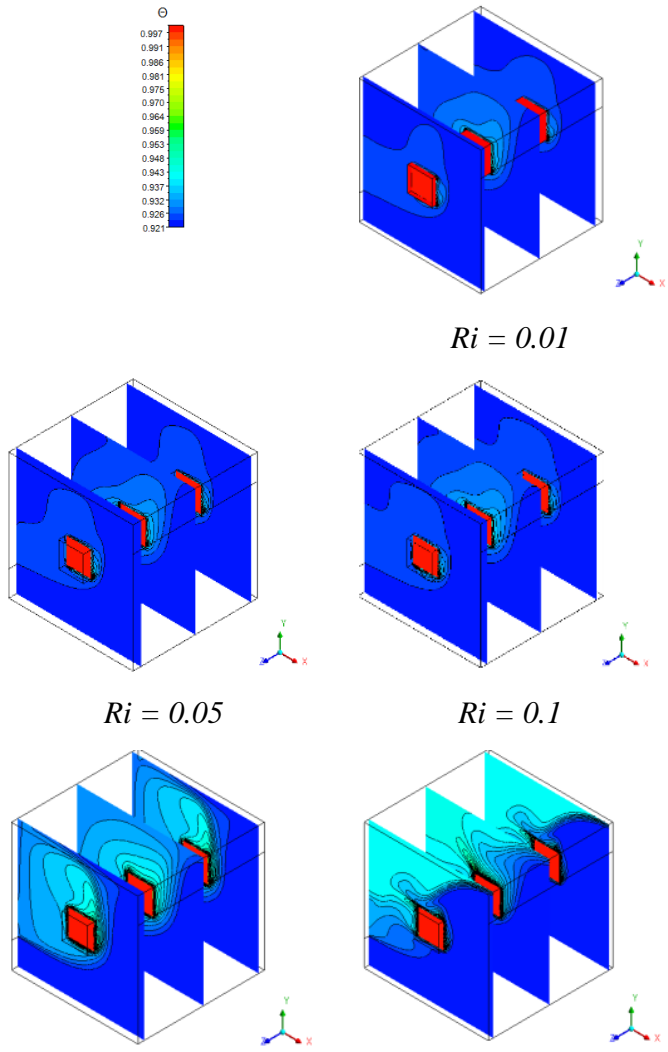

$R i=1$

$R i=2.5$
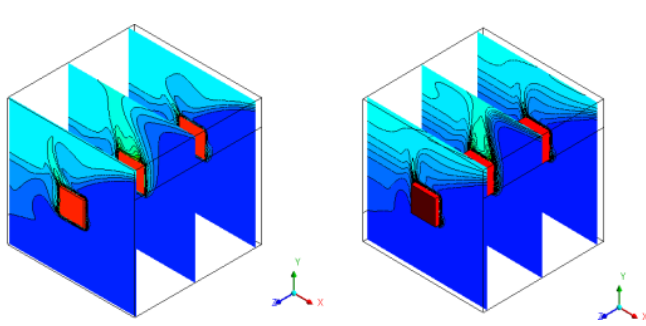

$R i=5$

$R i=10$
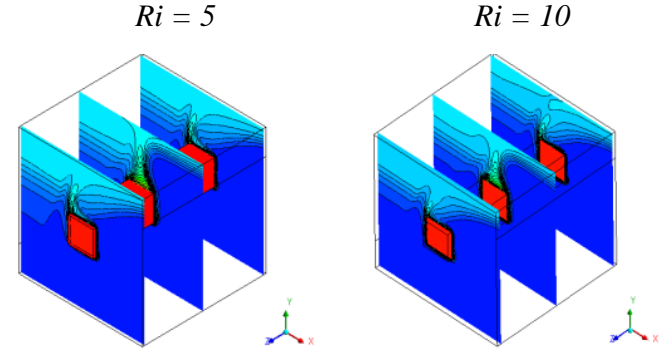

$R i=20$

$R i=30$

Fig. 9. Temperature fields in three dimensions for different $R i$ number $(\tau=100)$.

\subsection{Time-dependent heat and flow field}

Figure 11 demonstrates the evolution of the 3D flow and temperature patterns for $R i=20$. At initial time, $(\tau=1)$ the prevailing heat transfer mechanism inside the cavity is conduction where high 

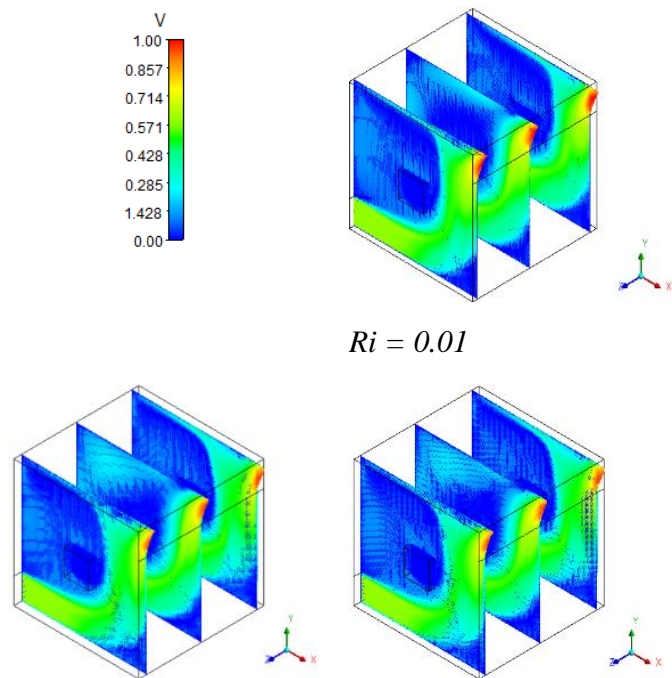

$R i=0.01$

$R i=0.05$

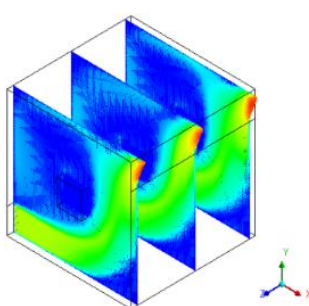

$R i=1$

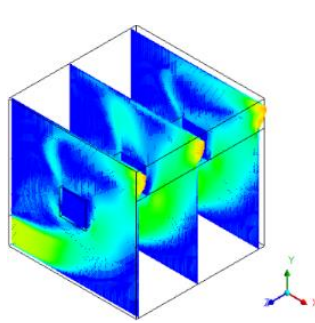

$R i=5$

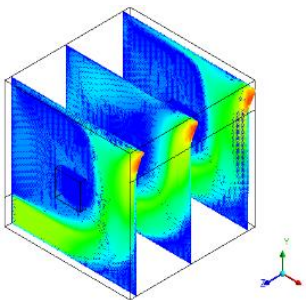

$R i=0.1$

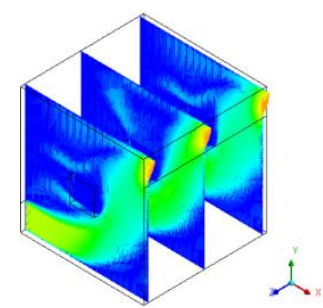

$R i=2.5$

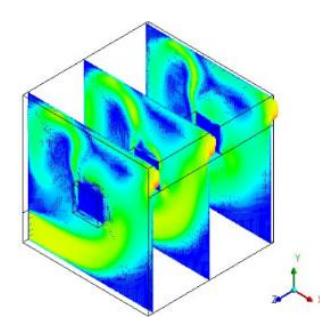

$R i=10$

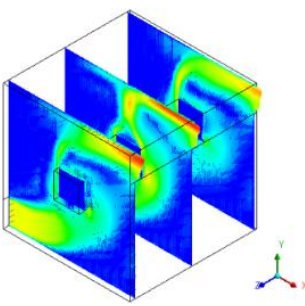

$R i=20$

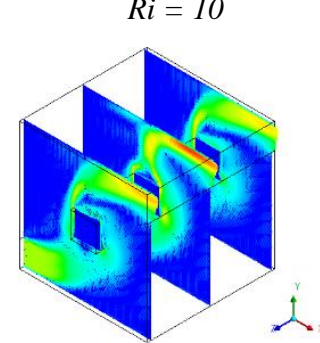

$R i=30$

Fig. 10. Three-dimensional velocity fields for different $R i$ values $(\tau=100)$.

temperature isotherms near the heated surface and uniformly distributed low temperature isotherms are noticed inside the enclosure.

It is observed that the flow entering from the lower inlet moves toward to right wall and right after the cylinder goes up toward the outlet of the cavity, which forms a high velocity zone. With increasing time, at $\tau=10$, the fluid heated up by the hot

cylinder creates a secondary circulation in the left top of the cavity. By elapsed time, $(\tau=22-100)$, this behavior disappears due to the fact that the effect of hot cylinder on the flow becomes more profound and the incoming fluid from the lower part of the enclosure moves up along the left wall of the cylinder canalizes the flow to the exit. As a result of that, the zone where maximum vertical velocity appears is displaced from the bottom of cavity under the heat source into the central position above the hot cylinder toward the outlet. It is worth nothing that a steady-state flow is observed at $\tau=$ 100 , which will be confirmed below.

In order to examine the temporal evolution of the temperature in the vicinity of the heat source, the temperature variations in dimensionless form at four points (marked in Fig. 1 and shown in Table 1) is monitored and displayed in Figs. 12a-d for thesmallest, moderate and largest $R i$ numbers studied in this work, representing different heat convection modes. It is evident from the figures that the largest and smallest temperatures are observed for $R i=1$ and 30, respectively, regardless of the location of temperature.

Table 1 Coordinates of points used from the region near the heat source

\begin{tabular}{|c|c|c|c|}
\hline & X & Y & Z \\
\hline Point 1 & 0.33 & 0.5 & 0.5 \\
\hline Point 2 & 0.66 & 0.5 & 0.5 \\
\hline Point 3 & 0.5 & 0.33 & 0.5 \\
\hline Point 4 & 0.5 & 0.66 & 0.5 \\
\hline
\end{tabular}

In the all points, temperature rises up till a certain time and then starts to decline with elapsing time. The temperature variation levels off after around $\tau=$ 100, which indicates the reach of steady-state regime. The difference between the magnitude of dimensionless temperature recorded for $R i=0.01$ and 1 is much smaller compared to that of $R i=1$ and 30 , implying that for a more effective cooling, the $R i$ number should be above the unity.

\subsection{Heat transfer rate}

In Fig. 13, we present the average $\mathrm{Nu}$ number versus the $R i$ to show the rate of transferred heat in the cavity with respect to the intensity of ventilation. We can see that with increasing $R i$, the average $\mathrm{Nu}$ number drops for $R i<1$, and exhibits an increment for $1<R i<30$. Similarly, this trend was observed by Abdelmassih et al. (2016).

For the Ri number values between For $0.01<R i<$ 1 , the value of Nusselt number is high in small values of $R i$ due to the forced convection caused by high speed of flow and the increasing of Richardson numbers causes a decrease in speed which means a decrease of Nusselt number. For $1<R i<30$, the $\mathrm{Nu}$ number increases as $R i$ increases because of the enhancement of coaction between the natural convection flow and the forced flow that enters from the inlet port. With increment of $R i$ number, 
A. Bouras et al. / JAFM, Vol. 14, No. 6 pp. 1869-1880, 2021.

the buoyancy force dominates the mixed convective flow, i.e. the natural convection prevails heat transfer between the considered enclosure and the mounted heat source. Considering the studied values of $R i$, we have proposed the following correlations to estimate the Nusselt number:

For $R i<1: N u=158.02 R i^{-0.091}$

For $1<R i<30: N u=143.17 R i^{0.044}$

We note that the maximum relative error between the measured values and those of the correlation does not exceed $3 \%$.

\section{CONCLUSION}

In this work, 3D turbulent mixed-convection in a vented cavity is studied. The influence of the variation of Richardson number, dimensionless time and dynamic parameters on the flow and temperature patterns is analyzed. The careful examinations of the gained results show that:

- The exchange between the pressure and buoyancy forces is controlled by the Richardson number, i.e. the heat transfer is
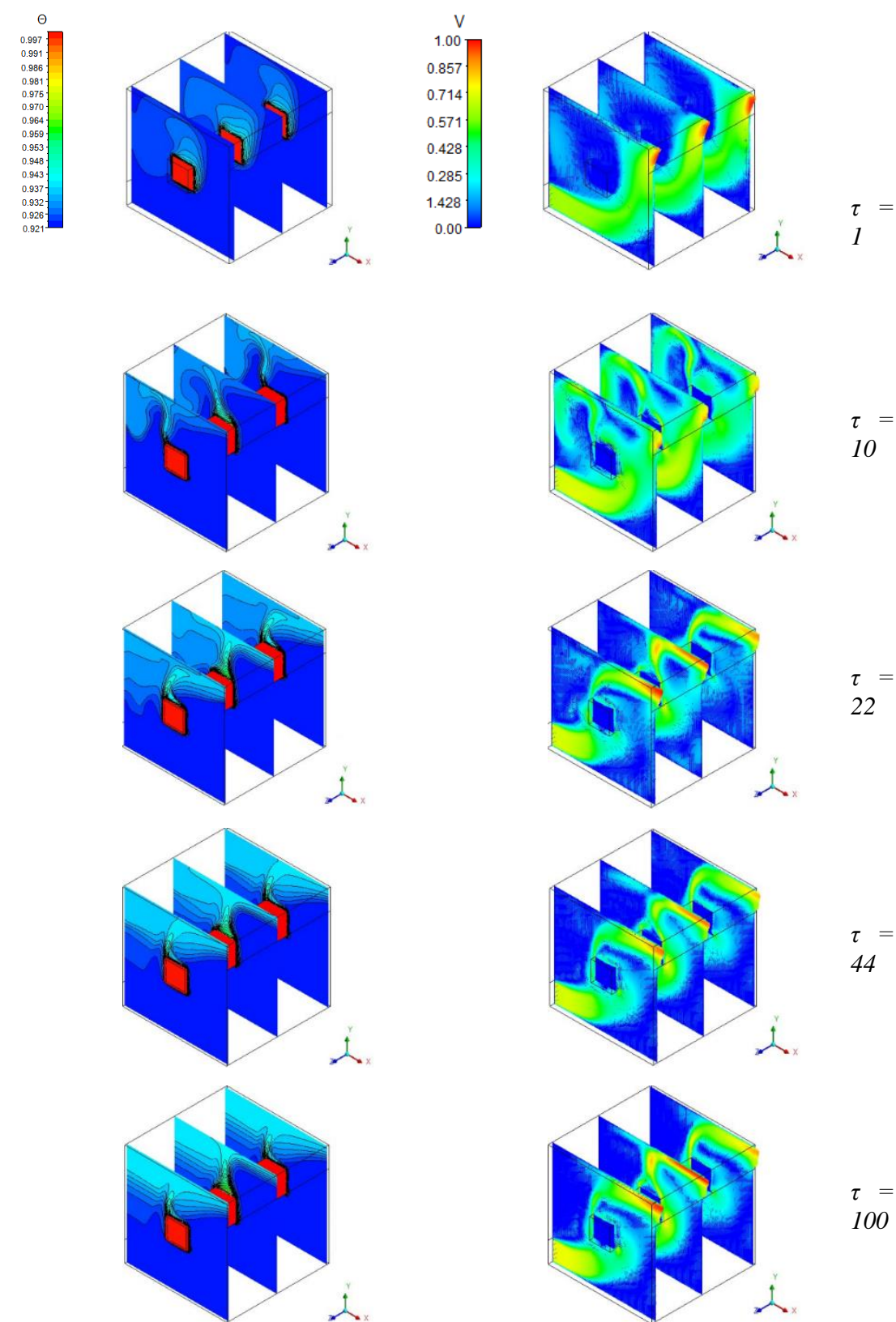
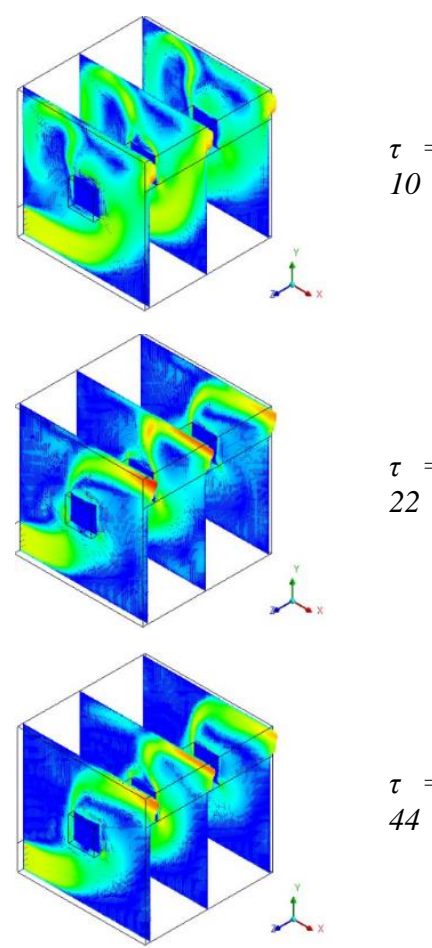

44

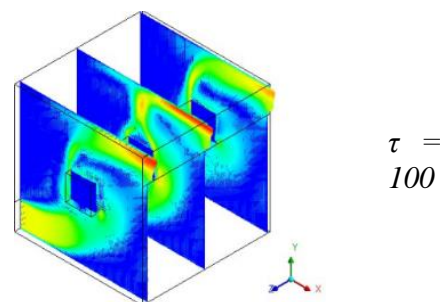

Fig. 11. Velocity (right) and temperature fields (left) in three-dimensions for $R i=20$ at different times: $\tau=1,10,22,44$, and 100 . 


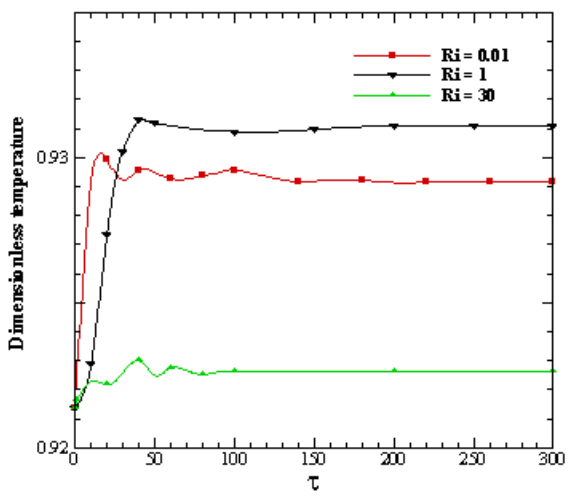

a) Point 1

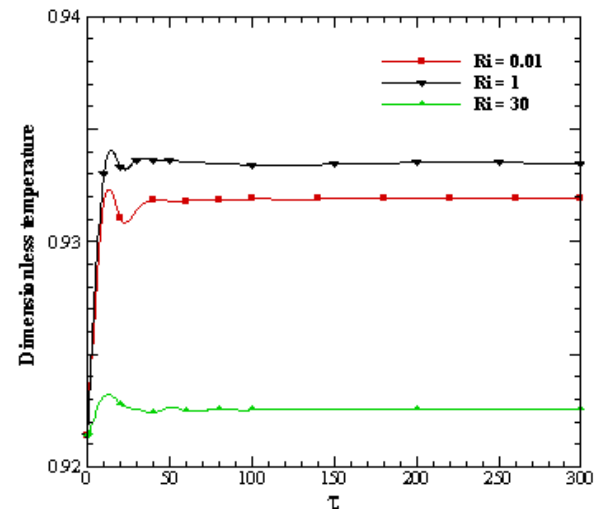

b) Point 2

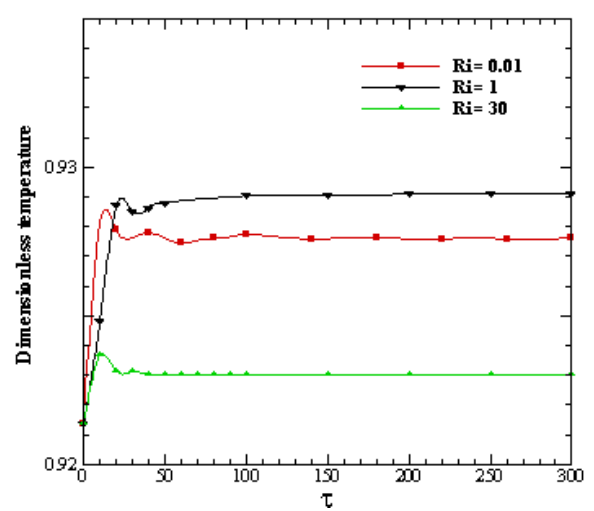

c) Point 3

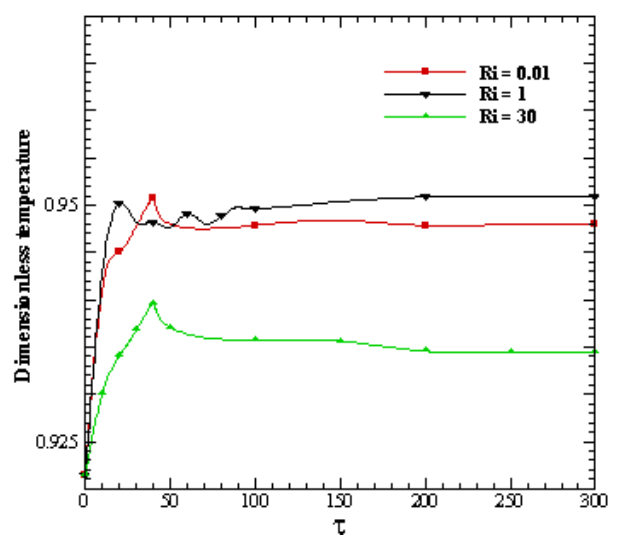

d) Point d

Fig. 12. Time evolution of dimensionless temperature at different points in the cavity.

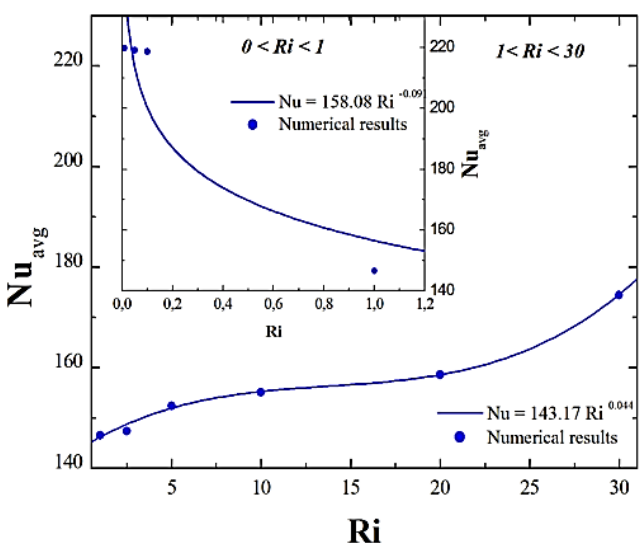

Fig. 13. Average Nusselt number vs Richardson number and proposed correlations.

dominated by buoyancy force for $1<R i<30$ and by the pressure force (forced convection) for $0.01<R i<1$.

- $\quad$ The average Nusselt number reduces for $R i<$ 1 , and increases for $1<R i<30$ with the increase in $R i$ number.

- The increase in time displaces the region of maximum vertical velocity from the bottom of the enclosure under the heat source into the central position over the heat source to the outlet and indicates the establishment of steady-state regime.

- A more effective cooling of the block is obtained for the higher value of $R i$ number (10 $<R i<30$ ) where the surface of the heat source is the hot one in the cavity.

- Correlations of the dependence of mean Nusselt number with Richardson number were proposed for the studied interval.

- The obtained results can be used in further investigation to improve the performance of industrial systems, in particular, the cooling of electronic components and devices.

- In the future, we target to study the effect of the conjunction of different hot blocks with aim of sufficient conditions of cooling.

\section{ACKNOWLEDGEMENTS}

The support and fund of the Directorate General of Scientific Research and Technological Development (DGSRTD) - to the LME laboratory in conducting this research is gratefully acknowledged (PRFU/A11N01UN030120190001).

\section{REFERENCES}

Abdelmassih, G., A. Vernet and J. Pallares (2016). Steady and unsteady mixed convection flow in a cubical open cavity with the bottom wall heated. International Journal of Heat and Mass Transfer 101, 682-691. 
Afolabi, S. I., A. O. Ojo, M. A. Oluleye and A. A. Ojo (2019). Convective heat transfer in a square cavity with a heat-generating body of different aspect ratios. International Journal of Engineering Research \& Technology 8 (6), 555-562.

Afrid, M. and A. Zebib (1991). Three-dimensional laminar and turbulent Natural convection cooling of heated blocks. Numerical Heat Transfer, Part A 19 (4), 404-423.

Alshomrani, A. S., S. Sivasankaran, A. A. Amer and A. Biswas (2019). Numerical study on convective flow in a three-dimensional enclosure with hot solid body and discrete cooling. Numerical Heat Transfer Part A: 76 (2), 1-13.

Amirouche, Y. and R. Bessaïh (2012). ThreeDimensional Numerical Simulation of Air Cooling of Electronic Components in a Vertical Channel. Fluid Dynamics and Materials Processing 8(3), 295-309.

Bouabdallah, S., D. Chati, B. Ghernout, A. Atia and A. Laouirat (2016). Turbulent mixed convection in enclosure containing a circular/ square heat source. International journal of heat and technology 34 (3), 446-454.

Bouabdallah, S., B. Ghernaout, A. Bellaouar, A. Bouras and A. Ghazel (2020). 3D Forced convection in a box containing two cylindrical heat sources, Advances in Modelling and Analysis B 63, (1-4), 20-25.

Burgos, J., I. Cuesta and C. Salueña (2016). Numerical study of laminar mixed convection in a square open cavity. International Journal of Heat and Mass Transfer 99, 599-612.

Calcagni, B., F. Marsili and M. Paroncini (2005). Natural convective heat transfer in square enclosures heated from below. Applied Thermal Engineering 25 (16), 2522-2531.

Chati, D., S. Bouabdallah and B. Ghernaout (2021a). Ventilation of square cavity containing a heat source. Defect and Diffusion Forum 406, 149-163.

Chati, D., S. Bouabdallah, B. Ghernaout, E. Tuncbilek, M. Arici and Z. Driss (2021b). Turbulent mixed convective heat transfer in a ventilated enclosure with a cylindrical/cubical heat source: a 3D analysis. Energy Sources, Part A: Recovery Utilization, and Environmental Effects.

Choi, C., H. W. Cho, M. Y. Ha and H. S. Yoon (2015). Effect of circular cylinder location on three-dimensional natural convection in a cubical enclosure. Journal of Mechanical Science and Technology 29 (3) 1307-1318

Doghmi, H., B. Abourida, L. Belarche, M. Sannad and M. Ouzaouit (2020). Three-dimensional mixed convection heat transfer in a partially heated ventilated cavity. Thermal Science 24(3B), 1895-1907.
Fontana, É., C. A. Capeletto, A. da Silva and V. C. Mariani (2013). Three-dimensional analysis of natural convection in a partially-open cavity with internal heat source. International Journal of Heat and Mass Transfer 61, 525-542.

Gibanov, N. and M. Sheremet (2017). Unsteady natural convection in a cubical cavity with a triangular heat source. International Journal of Numerical Methods for Heat \& Fluid Flow 27 (8), 1795-1813.

Gokulavani, P., M. Muthtamilselvan, M. A. Qasem and D.H. Doh (2020). Effects of orientation of the centrally placed heated baffle in an alternative configured ventilation cavity. The European Physical Journal Plus 135 (23).

Gupta, S. K., D. Chatterjee and B. Mondal (2015). Investigation of mixed convection in a ventilated cavity in the presence of a heat conducting circular cylinder. Numerical Heat Transfer Part A, 67 (1), 52-74.

Helmaoui, M., H. Laidoudi, A. Belbachir, A. Ayad and A. Ghaniam (2020). Forced convection heat transfer from a pair of circular cylinders confined in ventilated enclosure. Diffusion Foundations 26, 104-111.

Ivan, I. N. and A. S. Mikhail (2018). Conjugate mixed convection in a rectangular cavity with a local heater. International Journal of Mechanical Sciences 136, 243-251.

Kadari, A., N. E. Chemloul and S. Mekroussi (2018). Numerical investigation of laminar natural convection in a square cavity with wavy wall and horizontal fin attached to the hot wall. ASME, Journal of Heat Transfer 140(7), 072503 (15 pages).

Koufi, L., Z. Younsi, Y. Cherif and H. Naji (2017). Numerical investigation of turbulent mixed convection in an open cavity: Effect of inlet and outlet openings. International Journal of Thermal Sciences 116, 103-117.

Kuznetsov, G. V. and M. A. Sheremet (2010). Numerical simulation of convective heat transfer modes in a rectangular area with a heat source and conducting walls. ASME, Journal of Heat Transfer 132, 081401 (9 pages).

Laidoudi, H., M. Helmaoui, A. Belbachir, A. Ayad and A. Ghaniam, (2020). Effects of Inlet and Outlet Ports of Ventilated Square Cavity on Flow and Heat Transfer. Diffusion Foundations 26, 78-85.

Laouira, H., F. Mebarek-Oudina, A. K. Hussein, L. Kolsi, A. Merah and O. Younis (2020). Heat transfer inside a horizontal channel with an open trapezoidal enclosure subjected to a heat source of different lengths. Heat TransferAsian Research 49 (1), 406-423.

Mosharrof, Md. H., A. Ejaz, K. C. Prakash and S. Sumon (2019). Comparison of 2D and 3D numerical simulation of mixed convection inside a vented cavity for cold room 
A. Bouras et al. / JAFM, Vol. 14, No. 6 pp. 1869-1880, 2021.

applications. $\quad 8^{\text {th }} \quad$ BSME International Conference on Thermal Engineering.

Nardini, G., M. Paroncini and R. Vitali (2016). An Experimental and numerical analysis of natural convective heat transfer in a square cavity with five discrete heat sources. ASME Journal of Heat Transfer 138 (12).

Piña-Ortiz, A., J. F. Hinojosa, J. P. Xamán and J. M. A. Navarro (2018). Test of turbulence models for heat transfer within a ventilated cavity with and without an internal heat source. International Communications in Heat and Mass Transfer 94, 106-114.

Purusothaman, A., A. Baïri and N. Nithyadevi (2016). 3D natural convection on a horizontal and vertical thermally active plate in a closed cubical cavity. International Journal of Numerical Methods for Heat \& Fluid Flow 26 (8), $2528-2542$.

Rahman, Md. M., M. A. Alim, S. Saha and M. K. Chowdhury (2009). Effect of the presence of a heat conducting horizontal square block on mixed convection inside a vented square cavity. Nonlinear Analysis: Modelling and Control 14 (4), 531-548.

Rahman, Md. M., M. A. Alim, S. Saha and M. K. Chowdhury (2008). A numerical study of mixed convection in a square cavity with a heat conducting square cylinder at different Locations. Journal of Mechanical Engineering 39(2), 78-85.

Rahman, M. M., S. Parvin, N. A. Rahim, M. R. Islam, R. Saidur and M. Hasanuzzaman (2012). Effects of Reynolds and Prandtl number on mixed convection in a ventilated cavity with a heat-generating solid circular block. Applied Mathematical Modelling 36(5), 2056-2066.

Rajesh, K. P., V. Anbumalar, M. Krishnakumar, A. Ramakrishnan, P. S. Allwyn and A. V. Santhosh Kumar (2014). Numerical investigation of mixed convection heat transfer from block mounted on a cavity. Arabian Journal for Science and Engineering 39. 9187-9204.

Rodríguez, N. A., J. F. Hinojosa and J. Xamán (2015). Comparative study between experimental data and numerical results of turbulent mixed convection in a ventilated cavity. ASME, Journal of Heat Transfer 137, 545011-545015.

Stiriba, Y., J. A. Ferré and F. X. Grau (2013). Heat transfer and fluid flow characteristics of laminar flow past an open cavity with heating from below. International Communications in Heat and Mass Transfer 43, 8-15. 